\title{
RNA interference of acetylcholinesterase in the Asian citrus psyllid, Diaphorina citri, increases its susceptibility to carbamate and organophosphate insecticides.
}

\author{
Abdelaziz Kishk $^{1,2}$, Faraj Hijaz ${ }^{1}$, Helmy A. I. Anber ${ }^{2}$, Tsamoh K. AbdEl-Raof ${ }^{2}$, AbdEl-Hakeem \\ D. El-Sherbeni ${ }^{2}$, Sobhy Hamed ${ }^{2}$ and Nabil Killiny ${ }^{1, *}$
}

1 Department of Plant Pathology, IFAS, Citrus Research and Education Center, University of Florida, Lake Alfred, Florida, USA.

2 Department of Plant Protection, Faculty of Agriculture, Tanta University, Tanta, Egypt.

* Corresponding author. Tel.: +1-863-956-8833. E-mail: nabilkilliny@ufl.edu

Keywords: Diaphornia citri; RNA interference; acetylcholinesterase; insecticides resistance; organophosphates; carbamate.

Running title: Breaking down the insecticide resistance of D. citri. 


\section{Abstract}

2 The Asian citrus psyllid, Diaphorina citri Kuwayama (Hemiptera: Lividae) transmits the

3 Candidatus Liberibacter asiaticus, which causes citrus greening disease or Huanglongbing,

4 (HLB). To date, there is no efficient cure for HLB disease and the control of $D$. citri using

5 insecticides became the most important tools for the management of HLB. However, the

6 extensive use of insecticides could increase $D$. citri resistance to these insecticides. The objective

7 of this study was to investigate the effect of RNA interference of acetylcholinesterase $(A C h E)$ on

8 the mortality and susceptibility of $D$. citri to the four major insecticides used in Florida. In this

9 study, we used a consensus sequence derived from the two AChE genes and cholinesterase 2-like

10 (ChE-2-like) gene to target all of the three genes. Treatment with dsRNA-AChE increased the

11 mortality percentages of both nymphs and adults of $D$. citri. The mortality percentage increased

12 with the increase in the concentration of applied dsRNA-AChE, and the highest mortality (>

$1360 \%)$ was observed at the highest applied concentration $(125 \mathrm{ng} / \mu \mathrm{l})$. Treatments of nymphs or

14 adults with dsRNA- $A C h E$ down-regulated the expression of the three targeted genes of $D$. citri.

15 Silencing of $A C h E$ and $C h E$ in $D$. citri nymphs increased the susceptibility of emerged adults to

16 chlorpyrifos and carbaryl, which act as AChE inhibitors. However, treatment with dsRNA- $A C h E$

17 did not increase the susceptibility of emerged adults to imidacloprid, which acts as an agonist of

18 nicotinic acetylcholine receptors. In the same manner, treatment of adults with dsRNA- $A C h E$

19 increased their susceptibility to chlorpyrifos and carbaryl, but did not affect their susceptibility to

20 imidacloprid. The ANOVA did not show any significant increase in susceptibility of $D$. citri

21 adults to fenpropathrin after treatment with dsRNA-AChE, either as nymphs or as adults.

22 However, simple linear regression showed that treatment with dsRNA-AChE increased $D$. citri

23 susceptibility to fenpropathrin, which indicated that $A C h E$ could be involved in the metabolism 
1 of fenpropathrin. Our results indicated that silencing of $A C h E$ and $C h E$ genes in D. citri to

2 increase its susceptibility to insecticides could be a promising tool for the control of this

3 important vector.

4

5

6

7

10 greening disease, the most fatal disease of citrus around the world. HLB can cause tree decline,

11 reduces the quality of the fruit, and could result in tree death [1,2]. Also, D. citri decreases the

12 photosynthetic rate of the trees by excreting honeydew which causes sooty mold on leaf surfaces

13 [3]. The new shoots are essential for the oviposition and the development of nymphs, however

14 adults can survive and overwinter on the hardened leaves [4]. Both D. citri adults and nymphs

15 can transmit CLas, but nymphs were found to be more efficient [5].

17 citri in Florida citrus groves [6,7]. For the past six decades, the use of systemic insecticides

18 became the most common control measures for D. citri [8]. Organophosphates and carbamates

19 such as chlorpyrifos, dimethoate, malathion, aldicarb and carbaryl are the most commonly used

20 insecticides for D. citri management [9]. The organophosphates and carbamate act by inhibiting

21 acetylcholinesterase (AChE; EC 3.1.1.7), one of the important enzymes in the nervous system in

22 insects [10]. Acetylcholinesterase enzymes catalyze the hydrolysis of the neurotransmitting 23 agent, acetylcholine (ACh), to choline and acetic acid. Accumulation of acetylcholine in the 
1 intercellular space results in continuous stimulation of the receptors on the target cells. The

2 synthetic pyrethroid (fenpropathrin), which acts as sodium channel modulator, has also been

3 used for the control of D. citri $[11,12]$.

4 During the past decade, neonicoinoids have been found to be the most effective class of 5 insecticides for D. citri control [13]. In Florida, many of the systemic neonicotinoid insecticides

6 such as imidacloprid, thiamethoxam, and clothianidin are allowed to be used as soil applications,

7 but their use is limited to young trees [14]. Neonicotinoids act on insect nicotinic acetylcholine

8 receptors $(n A C h R s)$, which mediate fast cholinergic synaptic transmission in insect central

9 nervous system. Recently, imidacloprid has been extensively used for the control of D. citri

10 because it is more toxic to insects than vertebrates and persists systemically in plants [15].

11 The random and continuous use of insecticides caused several critical problems such as

12 insect resistance, residues in food products, and environmental pollution [16,17]. General

13 esterases (GEST), cytochrome P450 monooxygenases, and glutathione S-transferases (GST) are

14 the main detoxification enzymes controlling insecticide resistance in insects $[18,19]$.

15 Carboxyesterases (CarEs) are widely distributed in insects [20], and they are involved in several

16 essential physiological functions including insect development and behavior regulation,

17 neurotransmission, and hormone and pheromone metabolism [21]. In addition, CarEs play an

18 important role in the detoxification of xenobiotic compounds [22,23]. AChE, one of the most

19 important CarEs enzyme, plays an important role in the development of insecticide resistance 20 [24].

Unfortunately, the number of modes of action available for the control of D. citri are

22 limited. Consequently, various levels of insecticide resistance were observed in Florida as a 
1 result of using of the same class of insecticides or mode of action (i.e., acetylcholinesterase

2 inhibitors, sodium channel modulator) repeatedly [9,17]. The susceptibility of $D$. citri to

3 insecticides decreased with the increased expression of certain enzymes [9,17]. Consequently, it

4 has been a challenge for researchers to develop efficient strategies for D. citri control with low

5 environmental impact such as RNA interference. RNA interference (RNAi) was proposed by

6 many researchers as an ecofriendly control for D. citri [25-28].

7 RNAi is a post-transcriptional control mechanism involving degradation of target mRNA

8 which is mediated by small interfering RNAs (siRNAs) [29]. The phenomenon of gene silencing

9 has now been considered as a potential strategy for insect management. The selection of the

10 target gene and synthesis of double-stranded RNA (dsRNA) comprise a crucial component in the

11 application of this technology [30].

12 RNAi has emerged as a versatile and a promising molecular biology tool [31] for down-

13 regulating target gene expression in insects [32,33]. Previous reports showed that silencing of

14 genes through RNAi in insects could increase insect mortality, affect insect growth, increase

15 insecticide susceptibility, and prevent the development of insecticide resistance [25]. In the

16 present study, we hypothesize that silencing of $A C h E$ and $C h E$ genes using RNAi technique

17 through topical feeding application increases the susceptibility of $D$. citri to insecticides.

19 2. Materials and methods

$20 \quad$ 2.1. Asian citrus psyllid population

21 A laboratory susceptible populations of D. citri were continuously reared in a USDA-

22 APHIS/CDC-approved secured growth room at $25 \pm 2{ }^{\circ} \mathrm{C}$ with $60 \pm 5 \%$ relative humidity and $16: 8$

23 h (light:dark) photoperiod at the Citrus Research and Education Center (CREC), University of 
1 Florida, Lake Alfred, Florida, without exposure to insecticides. The insect colonies were reared

2 on Citrus macrophylla plants and caged using insect rearing cages $(60 \times 60 \times 90 \mathrm{~cm})$ included all

3 instar nymphs and adults. For the dsRNA application, the $4^{\text {th }}$ and $5^{\text {th }}$ instar nymphs were

4 collected using a camel hair brush while an aspirator was used to collect adult D. citri for dsRNA

5 and insecticides application.

\subsection{Constructing of dsRNA- $A C h E$ Gene sequencing of $A C h E$ and $C h E$}

The genome of Diaphorina citri possesses two acetylcholinesterase-like $(A C h E)$ genes; acetylcholinesterase-like-1 (XM_008477411.1), acetylcholinesterase-like-2 (XM_008482391.1),

9 and one cholinesterase 2-like (XM_008469625.1).

For dsRNA-AChE, a consensus sequence derived from the three gene sequences,

11 mentioned above, was used to design $A C h E$-specific primer sequences to target the two $A C h E$

12 genes of $D$. citri. The $A C h E$-consensus sequence was 489 bp in length. The dsRNA- $A C h E$ was

13 constructed using acetylcholineesterase-Like-1 (XM_00847711.1) from nucleotide 395 to 884 as

14 described by Kishk et al., 2017 [26].

DsRNA- $A C h E$ and irrelevant dsRNA-gfp (green fluorescent protein) which was used as

16 a control were synthesized using the method described by Killiny et al., 2014 [25].

\section{$17 \quad$ 2.3. Insecticides}

18 Laboratory populations of $D$. citri adults were tested with four insecticides targeting the

19 nervous system and belonging to different chemistry classes and modes of action as listed in

20 (Table 1). All treatments were formulated using analytical-grade insecticides. At least five

21 concentrations from each insecticide were prepared in acetone as follows: chlorpyrifos $(0.01,0.1$, 
$11,5,10,20 \mathrm{ng} / \mu 1)$, carbaryl $(0.1,1,10,100,200 \mathrm{ng} / \mu 1)$, fenpropathrin $(0.01,0.1,10,50,100$

$2 \mathrm{ng} / \mu \mathrm{l})$, imidacloprid $(0.001,0.01,0.05,0.1,1,5 \mathrm{ng} / \mu \mathrm{l})$. Insecticides solution were prepared and 3 used the day of the application.

\section{$4 \quad$ 2.4. Insecticides evaluations of adult $D$. citri using a leaf-dip bioassay}

Lethal concentrations that caused $50 \%\left(\mathrm{LC}_{50}\right)$ mortality to $D$. citri adults were determined

6 using a leaf-dip bioassay method [17,34]. $3-5 \mathrm{~mL}$ of a $1.5 \%$ agar solution were poured in $60-$

7 mm-diameter plastic disposable petri dish (Corning Incorporated, Corning, NY, USA) to form a

8 solidified bed. Citrus leaf disks (60-mm-diameter) were excised from fresh leaves collected from

9 citrus trees grown in the CREC grove without any exposure to insecticides. The leaf disks were

10 dipped for $30 \mathrm{~s}$ in the insecticide/acetone solution and allowed to air dry in a fume hood for $1 \mathrm{~h}$

11 before being placed on agar beds in the petri dishes. Leaf discs dipped in acetone alone were

12 used as a control. Using a camel hair brush, 15 newly emerged D. citri adults were transferred

13 into each petri dish. The petri dishes were wrapped with Parafilm (BEMIS Flexible Packaging,

14 Neenah, WI, USA) to keep the adults inside. Each concentration of each insecticide was

15 replicated four times ( $\mathrm{n}=60$ adults per concentration). All sealed petri dishes were moved to

16 USDA-APHIS/CDC-approved secured growth room $\left(25 \pm 2{ }^{\circ} \mathrm{C}, 60 \pm 5 \%\right.$ relative humidity, $16: 8 \mathrm{~h}$,

17 light:dark photoperiod).

18 The mortality of D. citri adults was assessed $24 \mathrm{~h}$ after exposure to the insecticides. The

19 adults of $D$. citri found on their side or back and unable to move when checked with a camel hair

20 brush were counted as dead.

\section{2.5. Topical feeding of $D$. citri $^{\text {th }}$ and $5^{\text {th }}$ instar nymphs with dsRNA- $A C h E$}


Five diluted concentrations of dsRNA- $A C h E$ were prepared using RNase-free water as

2 follows: $25,50,75,100$ and $125 \mathrm{ng} / \mu 1$. In addition, RNase-free water was used as a control. For

3 the topical feeding application as described by Killiny and Kishk 2017 [35], a $0.2 \mu 1$ dsRNA

4 droplet was topically applied to the ventral side of the thorax between the three pairs of legs of

$54^{\text {th }}$ and $5^{\text {th }}$-stage nymphs of D. citri via a $10 \mu 1$ Hamilton (Hamilton Company, Reno, NV)

6 syringe microapplicator $(0.2 \mu \mathrm{l})$. The droplet was allowed to be consumed through the stylet

7 completely for $60 \mathrm{sec}$ by the nymphs. Each concentration of dsRNA-AChE was replicated five

8 times. Twenty nymphs were treated for each concentration replicate $(\mathrm{n}=100)$. D. citri nymph

9 mortality was calculated after the emergence of the adults, usually 4-5 d following treatment.

10 The nymphs were considered dead if they were unable to move when checked with a camel hair

11 brush.

12 2.6. Insecticides application for $D$. citri adults emerged from nymphs treated with dsRNA-

$13 \quad$ AChE

14 After D. citri nymphs were treated with dsRNA-AChE as described above, the emerged

15 adults were transferred to petri dish containing citrus leaf disk and treated with insecticide

16 solutions at their $\mathrm{LC}_{50}$ concentration as described previously. Leaf discs dipped in acetone alone

17 were used as control. The mortality results of $D$. citri adults was evaluated after $24 \mathrm{~h}$.

\subsection{Topical feeding of $D$. citri adults with dsRNA- $A C h E$}

The same five diluted concentrations of dsRNA- $A \operatorname{ChE}(25,50,75,100$ and $125 \mathrm{ng} / \mu \mathrm{l})$

20 were used to treat adult D. citri with RNase-free water used as the control. D. citri newly

21 emerged adults were anaesthetized using $\mathrm{CO}_{2}$ before the application dsRNA. A $0.2 \mu 1$ dsRNA

22 droplet were applied using the microapplicator to the ventral side of the thorax between the three 
1 pairs of legs. The treated adults were transferred to untreated citrus leaves on petri dishes as a

2 food source at $25 \pm 2{ }^{\circ} \mathrm{C}$ with $60 \pm 5 \%$ relative humidity and $16: 8 \mathrm{~h}$ (light:dark) photoperiod in the

3 growth room. D. citri mortality was recorded after $48 \mathrm{~h}$ to determine the effect of dsRNA

4 treatments.

5 2.8. Insecticides bioassay for $D$. citri adults after treated with dsRNA- $A C h E$

6 After $D$. citri adults were treated with dsRNA- $A C h E$ as described above, live adults were

7 treated with the $\mathrm{LC}_{50}$ concentration of the four insecticides (chlorpyrifos, carbaryl, fenpropathrin

8 and imidacloprid) using the leaf-dip bioassay method as described above. For the control, the

9 leaves were dipped in acetone without insecticide.

\subsection{Gene expression analysis for adults treated dsRNA- $A C h E$}

Two days aftertreatment with dsRNA- $A C h E$, live adults were collected and kept in

12 RNALater (Invitrogen, Life Technologies, Carlsbad, CA, USA) until use. RNA was extracted

13 using TriZol ${ }^{\circledR}$ reagent $\left(\right.$ Ambion $^{\circledR}$, Life Technologies, NY, USA) in five biological replicates with

14 five adults in each. Using a NanoDrop 2000 spectrophotometer (Thermo Scientific, USA),

15 concentration and purity of isolated RNA was measured. For synthesizing cDNA, SuperScript

16 first-strand synthesis system (Invitrogen) with random hexamer primers was used as described in

17 the manufacturer's instructions. SYBR ${ }^{\circledR}$ Green PCR master mix (Applied Biosystems) was used

18 to perform quantitative PCR (qPCR). For each treatment, three technical replicates per biological

19 replicate were analyzed using an ABI 7500 Real-Time PCR System (Applied Biosystems).

20 Primers of three targeted genes, and GFP were used to measure the gene expression as listed in

21 Kishk et al., 2017 [26]. To compare the relative expression of studied genes, the $2^{-\Delta \Delta C \mathrm{~T}}$ method

22 [36] was used. Actin was used as the reference gene to compare the relative gene expression 
1 among treatments and the control. GFP was used as an irrelevant gene and the non-target gene

2 was $\alpha$-tubulin (control).

\subsection{Statistical analysis}

Data was analyzed using JMP version 9.0 (SAS Institute Inc.,). All mortality data were

5

$12 A C h E$ and the observed mortality percentages.

\section{3. Results}

$15 \quad 3.1$ Toxicity of insecticides on $\boldsymbol{D}$. citri adults using leaf-dip bioassay

17 The four selected insecticides were toxic to the $D$. citri adults. Imidacloprid was the most toxic 18 among the four selected insecticides, followed by chlorpyrifos, fenpropathrin, and carbaryl 19 (Table 2).

\section{2. dsRNA- $A C h E$ treatments increased $D$. citri nymph mortality}

Five concentrations of dsRNA- $A C h E$ and RNase-free water as a control were applied to

22 the $4^{\text {th }}$ and $5^{\text {th }}$ instar nymphs of D. citri by topical feeding. The mortality of all dsRNA-treated 
1 nymph was higher than that of the control (RNase-free water), except for the lowest

2 concentration $(25 \mathrm{ng} / \mu \mathrm{l})$ (Fig. 1A). The mortality increased by increasing the concentration of

3 dsRNA-AChE (Fig. 1A). Significant differences were found in mortality rate among all dsRNA-

4 treated nymphs (Fig. 1A). The highest mortality (63.3\%) was observed at the highest applied

5 dsRNA-AChE concentration $(125 \mathrm{ng} / \mu \mathrm{l})$. In agreement with the Tukey's test results, the simple

6 linear regression also showed that the mortality rate was dependent on the concentration of 7 dsRNA- $A C h E$ (Fig. 1A).

\subsection{Treatments of nymphs with dsRNA- $A C h E$ down-regulated the gene expression of the}

9 three targeted genes in emerged $D$. citri adults

Our results showed that the expression levels for three targeted genes were down-

11 regulated in adults that emerged from dsRNA-treated nymphs compared with controls (dsRNA-

$12 g f p$ and RNase-free water) (Fig. 2A,B,C). The gene expression levels of the targeted genes

13 decreased with increasing the concentration of dsRNA-AChE; the highest effect on gene

14 expression levels of all targeted genes was observed at $125 \mathrm{ng} / \mu 1$, AChE-like-1 (0.48), ChE-2-

15 like (0.51) and AChE-like-2 (0.60) respectively, whereas the lowest effect was observed at 25

$16 \mathrm{ng} / \mu 1$. The greatest reduction in expression level was found with AChE-like-1, while the lowest

17 effect was with $A C h E$-like-2. There was no effect of the dsRNA-gfp treatment on the expression

18 levels of the three targeted genes. Moreover, there were no significant differences on the

19 expression levels of ??-tubulin among all the treatments (Fig. 2D). 
To determine the effect of dsRNA- $A C h E$ on insecticide susceptibility of $D$. citri adults

2 emerged from treated nymphs, we used the $\mathrm{LC}_{50}$ concentration of four insecticides (chlorpyrifos,

3 carbaryl, fenpropathrin and imidacloprid).

The simple linear regression (SLR) showed that adults emerged from nymphs treated

5 with dsRNA- $A C h E$ were more susceptible to carbaryl than those emerged from non-treated

6 nymphs (Fig. 3A). As shown in Fig 3A, the adults emerged from nymphs treated with $125 \mathrm{ng} / \mu \mathrm{l}$

7 dsRNA- $A C h E$ were more susceptible to carbaryl (62.2\% mortality) than the adults emerged from

8 nymphs that were treated with RNase-free water (42.2\% mortality).

9 In the same manner, the SLR showed that the susceptibility of adults to chlorpyrifos was

10 increased if they $\left(4^{\text {th }}\right.$ instar) were previously treated with dsRNA- $A C h E$ (Fig. $\left.3 \mathrm{~B}\right)$. The emerged

11 adults from nymphs treated with $125 \mathrm{ng} / \mu \mathrm{ldsRNA}-A C h E$ were more susceptible to chlorpyrifos

12 (68.9\% mortality) than those emerged from nymphs treated with RNase-free water $(48.9 \%$

13 mortality) (Fig. 3B).

14 For fenpropathrin, no significant differences in mortality were observed between adults

15 emerged from nymphs treated with dsRNA- $A C h E$ and those emerged from nymphs treated with

16 RNase-free water. However, the linear regression showed that the mortality rate was increased

17 by the application of the dsRNA- $A C h E$ (Fig. 3C).

The SLR showed that treatment of psyllid nymphs with dsRNA- $A C h E$, did not increase

19 the susceptibility of emerging adults to imidacloprid (Fig. 3D). In agreement with the SLR result,

20 the Tukey's test also did not show any significant difference in adult mortality to imidacloprid

21 insecticide between adults emerged from nymphs treated with dsRNA-AChE and those emerged

22 from nymphs treated with RNase-free water (Fig. 3D). 


\section{5. dsRNA- $A C h E$ treatments increased the mortality of adult $D$. citri}

The same five concentrations of dsRNA- $A C h E$ and water were applied to the $D$. citri

3 adults using topical application. The SLR showed that the dsRNA- $A C h E$ application increased

4 the mortality of adult psyllids (Fig. 1B). In agreement with the SLR, the Tukey's test also

5 showed that the mortality rate of all the dsRNA-AChE-treated adults was significantly higher

6 than control (Fig. 1B). Furthermore, the mortality rate of D. citri adults increased with increasing

7 concentration of dsRNA- $A C h E$ (Fig. 1B). Treatment using dsRNA- $A C h E$ at $125 \mathrm{ng} / \mu 1 \mathrm{caused}$ the

8 highest mortality ( $65.0 \%)$ followed by $100 \mathrm{ng} / \mu 1$ which caused $56.0 \%$ mortality.

9 3.6. Treatments of adults with dsRNA- $A C h E$ down-regulated the genes expression of the 10 three targeted genes

11 The expression levels for three targeted genes were also down-regulated in adult $D$. citri 12 upon treatment with dsRNA- $A C h E$ compared with controls (dsRNA- $g f p$ and RNase-free water) 13 (Fig. 2E,F,G). The gene expression levels of the three targeted genes also decreased with 14 increasing concentration of dsRNA-AChE. Moreover, there were no significant differences on 15 the expression levels of ??-tubulin among all the treatments (Fig. 2D). There were no significant 16 differences between treatments with RNase-free water and dsRNA-gfp. The highest reduction of 17 expression level of the targeted genes was recorded when treated with dsRA- $A C h E$ at the 18 highest concentration $(125 \mathrm{ng} / \mu \mathrm{l})$ and the least effect was found at (25 ng/ $\mu \mathrm{l}) \mathrm{dsRNA}-A C h E$ (Fig $192 \mathrm{E}, \mathrm{F}, \mathrm{G})$. 
In this experiment, we investigated the effect of dsRNA- $A C h E$ on the susceptibility of $D$.

2 citri adults to the four selected insecticides using their $\mathrm{LC}_{50}$ concentrations. The SLR showed

3 that treatment of adult psyllids with dsRNA-AChE increased their sensitivity to carbaryl (Fig.

4 4A). In agreement with the SLR, adults treated with $50,75,100$, and $125 \mathrm{ng} / \mu \mathrm{l}$ were more

5 susceptible to carbaryl than the controls (Fig. 4A). However, no significant difference in

6 mortality was observed between the control psyllids and those treated with the lowest

7 concentration $(25 \mathrm{ng} / \mu \mathrm{l})$ of dsRNA-AChE.

The SLR showed that D. citri adults became more susceptible to chlorpyrifos upon

9 treatment with dsRNA-AChE (Fig. 4B). The Tukey's test also showed that the mortality of adults

10 treated with $125 \mathrm{ng} / \mu \mathrm{l}$ and $100 \mathrm{ng} / \mu \mathrm{l}$ with dsRNA-AChE was higher than the control. However,

11 results were non-significant at lower concentrations (25, 50, and $75 \mathrm{ng} / \mu 1 \mathrm{dsRNA}-A C h E)$ (Fig.

12 4B).

13 Although the SLR showed that the susceptibility of D. citri adults to fenpropathrin 14 increased after treatment with dsRNA-AChE (Fig. 4C), the Tukey's test did not show any 15 differences between the treatments and the controls (Fig. 4C).

The SLR and Tukey's test showed that $D$. citri susceptibility to imidacloprid was not

17 affected upon treatment with dsRNA- $A C h E$ (Fig 4D). In addition, the SLR and the Tukey's ( $P>$

180.05 ) test showed that treatment with dsRNA-AChE did not increase the mortality of D. citri

19 adults to acetone which was used as a control insecticide (Fig. 4E). Acetone caused only 4.4\%

20 mortality when adults were treated at $125 \mathrm{ng} / \mu 1 \mathrm{dsRNA}-A C h E$. 
11 effective, whereas carbaryl was the least effective insecticide among the four tested insecticides.

12 In agreement with our result, previous studies also showed that neonicotinoids were the most

13 effective class of insecticides for control of $D$. citri [13]. Our results were comparable to other

14 results obtained from previous laboratory studies. It has been shown that $D$. citri adults were

15 more susceptible to imidacloprid ( $\mathrm{LD}_{50}$ value $\left.0.004 \mathrm{ng} / \mathrm{insect}\right)$, followed by chlorpyrifos $\left(\mathrm{LD}_{50}=\right.$

$160.25 \mathrm{ng} /$ insect$)$, fenpropathrin $\left(\mathrm{LD}_{50}=0.30 \mathrm{ng} / \mathrm{insect}\right)$ and carbaryl $\left(\mathrm{LD}_{50}=3.92 \mathrm{ng} / \mathrm{insect}\right) \mathrm{using}$

17 topical application bioassay [17]. Using leaf-dip bioassay, it was found that fenpropathrin $\left(\mathrm{LC}_{50}=\right.$

$180.24 \mathrm{ng} / \mu \mathrm{l})$ was the most toxic insecticide to $D$. citri adults, followed by imidacloprid $\left(\mathrm{LC}_{50}=\right.$

$190.31 \mathrm{ng} / \mu \mathrm{l})$, chlorpyrifos $\left(\mathrm{LC}_{50}=1.12 \mathrm{ng} / \mu \mathrm{l}\right)$ and carbaryl $\left(\mathrm{LC}_{50}=18.84 \mathrm{ng} / \mu \mathrm{l}\right)$ at $27^{\circ} \mathrm{C}[40]$.

22 study, field populations of $D$. citri were more resistant to fenpropathrin, imidacloprid, malathion,

23 and thiamethoxam than the laboratory susceptible population. The $\mathrm{LD}_{50}$ values for field 
1 populations of $D$. citri were significantly higher than the those from the laboratory susceptible

2 population [17].

RNA interference has been widely used to knockdown the gene expression in insects.

4 The effectiveness of RNAi depends on many factors including the delivery method of the

5 dsRNA [41]. In the present study, we used topical feeding application for dsRNA treatments for

6 both nymphs and adults of $D$. citri. The dsRNA droplet was topically applied on the ventral side

7 of the thorax between the three pairs of legs [25,35]. Compared with the other methods of

8 delivery, delivery of dsRNA using topical feeding application has many advantages. It delivers

9 the precise dose, minimizes the possibility of the dsRNA degradation, and reduces the mortality

10 of small and soft insects during the application [35].

11 Gene expression analysis for the $A C h E$ genes in the different developmental stages of $D$.

12 citri showed that the expression levels in the $4^{\text {th }}$ and $5^{\text {th }}$ nymph instars were higher than first,

13 second, and third nymph instars [26]. Our previous results showed that the expression levels in

14 adults were slightly lower than the $4^{\text {th }}$ and $5^{\text {th }}$ instar nymphs [26]. In the current work, we treated

15 the $4^{\text {th }}$ and $5^{\text {th }}$ instar nymphs of $D$. citri using dsRNA-AChE for silencing the $A C h E$ and $C h E$

16 genes. The silencing of the targeted genes increased the mortality percentages in both emerged

17 adults from treated nymphs and directly treated adults.

In agreement with our results, oral delivery of several dsRNAs (cathepsin D, chitin

19 synthase and inhibitor of apoptosis) using an artificial diet also increased the mortality in

20 nymphs and adult of D. citri [28]. Additionally, silencing the abnormal wing disc (awd) gene in

21 nymphs using dsRN-awd increased the mortality rate of D. citri [42]. Furthermore, dsRNA- 
$1 D c M P 20$ delivery through soaking mediated silencing of the muscle protein 20 and increased the

2 mortality rates of D. citri nymphs [27].

3 Our results showed that silencing of $A C h E$ and $C h E$ by dsRNA-AChE increased D. citri

4 susceptibility to carbaryl and chlorpyrifos more than fenpropathrin and imidacloprid.

5 Chlorpyrifos and carbaryl act by inhibiting acetylcholinesterase (AChE) [11], whereas

6 fenpropathrin acts as sodium channel modulator and imidacloprid acts as an agonist of nicotinic

7 acetylcholine (nAChR) receptor [11].

8 Although the Tukey's test did not show any differences in mortality percentage to 9 fenpropathrin between dsRNA-AChE treated D. citri and the control, the SLR showed that the 10 susceptibility of $D$. citri adults to fenpropathrin was increased upon treatment with dsRNA$11 A C h E$ as either nymphs or adults. The slight increase in the susceptibly of D. citri to 12 fenpropathrin indicated that $A C h E$ and $C h E$ could be involved in the metabolism of 13 fenpropathrin which requires a splitting of the ester bond. Esterases and mixed-function oxidases 14 play a major role in pyrethroid metabolism [43]. In agreement with this assumption, previous 15 studies also showed that $A C h E$ enzyme catalyzes the hydrolysis of esters other than acetylcholine 16 and its derivatives. For example, AChE from Pseudomonas aeruginosa PAO1 was able to 17 hydrolyze artificial esters, but with lower catalytic efficiency compared to acetylthiocholine and 18 propionylthiocholine [44].

Like D. citri, most insects contain two copies of $A C h E$ [45]. The presence of two AChE

20 genes in many insects has attracted the attention of many scientist to study their functions and

21 roles in insecticide resistance [45]. Although most insects contain two copies of $A C h E$, it is 22 believed that only one of them is active. Because the gene expression of $A C h E 2$ was positively 
1 correlated with the enzymatic activity of $A C h E$, it was suggested that $A C h E 2$ rather than $A C h E 1$

2 was the major $A C h E$ in the silkworm, Bombyx mori [46]. Using computational analyses, Lu et al.

3 (2012) suggest that the $A C h E 1$ protein was catalytically active in red flour beetle (Tribolium

4 castaneum), whereas $A C h E 2$ was not efficient [45]. In agreement with the computational

5 analyses, silencing of TcAcel in Tribolium castaneum (larvae) increased their mortality and

6 susceptibilities to anticholinesterase insecticides including two cabamates (carbofuran and

7 carbaryl) and two organophosphates (malathion and dichlorvos) [47]. On the other hand,

8 silencing TcAce2 did not affect insect mortality and insecticide susceptibility, but affected insect

9 development, number of laid eggs, and egg hatching [47]. The previous results indicated that

10 TcAcel plays a role in cholinergic functions, whereas TcAce 2 plays an important role in female

11 reproduction, embryo development, and growth of offspring [47]. Because the function of $A C h E$

12 genes has not been determined in D. citri yet, we targeted both copies of AChE to silence this

13 gene. Further study is needed to identify which of these two $A C h E$ genes has cholinergic

14 functions in D. citri.

In agreement with our results, the susceptibility of $D$. citri to imidacloprid was increased

16 upon silencing of CYP4, an important group of enzymes involved in the metabolism of

17 xenobiotics in insects, using RNAi [25]. In conclusion, our findings showed that silencing of

$18 A C h E$ and $C h E$ genes in D. citri could be used as a promising tool to control this important

19 vector. Our results showed that silencing of $A C h E$ and $C h E$ genes in D. citri increased their

20 mortality and susceptibility to carbaryl and chlorpyrifos, which target $A C h E$. Combining new

21 technologies such as RNAi and traditional pesticide applications may reduce the amount of

22 pesticides required to control the Asian citrus psyllid and help reduce environmental impact of

23 toxic pesticides used in agriculture. Our current findings suggest that $D$. citri susceptibility to 
1 carbamate and organophosphate insecticides could be enhanced in the field if they were

2 previously exposed to dsRNA- $A C h E$. However, several challenges have to be resolved before

3 this becomes practical in the field.

\section{Acknowledgement}

5 This work was supported with grant number 201500955-04 received from SCRI, NIFA-

6 USDA. AK was supported by a scholarship from the Egyptian government. We acknowledge our

$7 \quad$ lab members for the technical assistance and the useful discussion. 


\section{5 . References}

2 [1] S.E. Halbert, K.L. Manjunath, Asian citrus psyllids (Sternorrhyncha $\square$ : Psyllidae) and 3 greening disease of citrus $\square$ : a literature review and assessment of risk in Florida, Fla. $4 \quad$ Entomol. 87 (2004) 330-353.

5 [2] H.D. Catling, Distribution of the psyllid vectors of citrus greening disease, with notes on Mycopathologia 148 (1999) 141-147.

9 [4] J.M. Bové, Huanglongbing: a destructive, newly-emerging, century-old disease of citrus, J. Plant Pathol. 88 (2006) 7-37.

11 [5] E.D. Ammar, R. Alessandro, R.G. Shatters Jr, D.G. Hall, Behavioral, ultrastructural and 12 chemical studies on the honeydew and waxy secretions by nymphs and adults of the Asian 13 citrus psyllid Diaphorina citri (Hemiptera: Psyllidae), PLoS One 8 (2013) e64938.

14 [6] M.E. Rogers, General pest management Considerations, Citrus Ind. 89 (2008) 12-17.

15 [7] M.E. Rogers, P.A. Stansly, L.L. Stelinski, 2012 Florida citrus pest management guide $\square$ : 16 Asian citrus psyllid and citrus leafminer, Uf-Ifas Eny-734. (2012). 17 http://edis.ifas.ufl.edu/pdffiles/IN/IN68600.pdf. (accessed: 24.05.2017)

18 [8] J.A. Qureshi, P.A. Stansly, Integrated approaches for managing the Asian citrus psyllid 19 Diaphorina citri (Homoptera $\square$ : Psyllidae) in Florida, Proc. Fla. State Hort. Soc. 120 (2007) 110-115.

21 [9] S. Tiwari, L.L. Stelinski, M.E. Rogers, Biochemical basis of organophosphate and carbamate resistance in Asian citrus psyllid, J. Econ. Entomol. 105 (2012) 540-548.

[10] K.Y. Zhu, J. Gao, Increased activity associated with reduced sensitivity of acetylcholinesterase in organophosphate-resistant greenbug, Schizaphis graminum 
2 [11] M.E. Rogers, P.A. Stansly, L.L. Stelinski, Asian citrus psyllid and citrus leafminer, in:

(Homoptera: Aphididae), Pestic. Sci. 55 (1999) 11-17.

M.E. Rogers, L.W. Timmers, T.M. Spann (Eds.), Florida Citrus Pest Manag. Guid., University of Florida, Institute of Food and Agriculture Science Extension Publication no. SP-43, Gainesville, FL, 2008: pp. 43-50.

[12] D.R. Boina, J.R. Bloomquist, Chemical control of the Asian citrus psyllid and of Huanglongbing disease in citrus, Pest Manag. Sci. 71 (2015) 808-823.

[13] E.E. Grafton-Cardwell, L.L. Stelinski, P.A. Stansly, Biology and management of Asian citrus psyllid, vector of the Huanglongbing pathogens, Annu. Rev. Entomol. 58 (2013) $413-432$.

[14] J.A. Qureshi, B.C. Kostyk, P.A. Stansly, Effectiveness of selective insecticides to control Asian citrus psyllid and citrus leafminer during leaf flushing, Proc. Fla. State Hort. Soc. $124(2011) 85-89$.

[15] K. Matsuda, S.D. Buckingham, D. Kleier, J.J. Rauh, M. Grauso, D.B. Sattelle, Neonicotinoids: insecticides acting on insect nicotinic acetylcholine receptors, Trends Pharmacol. Sci. 22 (2001) 573-580.

[16] A.X. Silva, G. Jander, H. Samaniego, J.S. Ramsey, C.C. Figueroa, Insecticide resistance mechanisms in the green peach aphid Myzus persicae (Hemiptera: Aphididae) I: A transcriptomic survey, PLoS One 7 (2012) e36366.

[17] S. Tiwari, R.S. Mann, M.E. Rogers, L.L. Stelinski, Insecticide resistance in field populations of Asian citrus psyllid in Florida, Pest Manag. Sci. 67 (2011) 1258-1268.

[18] Z. Gui, C. Hou, T. Liu, G. Qin, M. Li, B. Jin, Effects of insect viruses and pesticides on glutathione S-transferase activity and gene expression in Bombyx mori, J. Econ. Entomol. 
102 (2009) 1591-1598.

[19] Z. Yang, H. Yang, G. He, Cloning and characterization of two cytochrome $\mathrm{P}_{450}$ CYP6AX1 and CYP6AY1 cDNAs from Nilaparvata lugens Stål (Homoptera: Delphacidae), Arch. Insect Biochem. Physiol. 64 (2007) 88-99.

[20] C. Strode, C.S. Wondji, J.P. David, N.J. Hawkes, N. Lumjuan, D.R. Nelson, D.R. Drane, S.H.P.P. Karunaratne, J. Hemingway, W.C. Black, H. Ranson, Genomic analysis of detoxification genes in the mosquito Aedes aegypti, Insect Biochem. Mol. Biol. 38 (2008) $113-123$.

[21] P. Taylor, Z. Radić, The cholinesterases: from genes to proteins, Annu. Rev. Pharmacol. Toxicol. 34 (1994) 281-320.

[22] J.A. Baum, T. Bogaert, W. Clinton, G.R. Heck, P. Feldmann, O. Ilagan, S. Johnson, G. Plaetinck, T. Munyikwa, M. Pleau, T. Vaughn, J. Roberts, Control of coleopteran insect pests through RNA interference, Nat. Biotechnol. 25 (2007) 1322-1326.

[23] X. Li, M.A. Schuler, M.R. Berenbaum, Molecular mechanisms of metabolic resistance to synthetic and natural xenobiotics, Annu. Rev. Entomol. 52 (2007) 231-253.

[24] Y. Kono, T. Tomita, Amino acid substitutions conferring insecticide insensitivity in Aceparalogous acetylcholinesterase, Pestic. Biochem. Physiol. 85 (2006) 123-132.

[25] N. Killiny, S. Hajeri, S. Tiwari, S. Gowda, L.L. Stelinski, Double-stranded RNA uptake through topical application, mediates silencing of five CYP4 genes and suppresses insecticide resistance in Diaphorina citri, PLoS One 9 (2014) e110536.

[26] A. Kishk, H.A.I. Anber, T.K. AbdEl-Raof, A.D. El-Sherbeni, S. Hamed, S. Gowda, N. Killiny, RNA interference of carboxyesterases causes nymph mortality in the Asian citrus psyllid, Diaphorina citri, Arch. Insect Biochem. Physiol. 94 (2017) e21377. 
1 [27] X. Yu, G. Siddarame, N. Killiny, Double stranded RNA delivery through soaking, 2 mediates silencing of the muscle protein 20 and increases mortality to the Asian citrus 3 psyllid, Diaphorina citri, Pest Manag. Sci. (2017) doi:10.1002/ps.4549..

4 [28] D.M. Galdeano, M.C. Breton, J.R.S. Lopes, B.W. Falk, M.A. Machado, Oral delivery of 5 double-stranded RNAs induces mortality in nymphs and adults of the Asian citrus psyllid, $6 \quad$ Diaphorina citri, PLoS One 12 (2017) e0171847.

7 [29] A. Fire, S. Xu, M.K. Montgomery, S.A. Kostas, S.E. Driver, C.C. Mello, Potent and 8 specific genetic interference by double-stranded RNA in Caenorhabditis elegans, Nature. $9391(1998) 806-811$.

10 [30] R. Katoch, N. Thakur, Insect gut nucleases: a challenge for RNA interference mediated 11 insect control strategies, Int. J. Biochem. Biotechnol. 1 (2012) 198-203.

12 [31] A.D. Singh, S. Wong, C.P. Ryan, S. Whyard, Oral delivery of double-stranded RNA in 13 larvae of the yellow fever mosquito, Aedes aegypti: implications for pest mosquito 14 control, J. Insect Sci. 13 (2013) e69.

15 [32] J.S. Whangbo, C.P. Hunter, Environmental RNA interference, Trends Genet. 24 (2008) $16 \quad 297-305$.

17 [33] M. Jinek, J.A. Doudna, A three-dimensional view of the molecular machinery of RNA 18 interference, Nature 457 (2009) 405-412.

19 [34] N. Prabhaker, S.J. Castle, N.C. Toscano, Susceptibility of immature stages of Homalodisca coagulata (Hemiptera: Cicadellidae) to selected insecticides, J. Econ. Entomol. 99 (2006) 1805-1812.

22 [35] N. Killiny, A. Kishk, Delivery of dsRNA through topical feeding for RNA interference in 23 the citrus sap piercing-sucking hemipteran, Diaphorina citri, Arch. Insect Biochem. 
Physiol. 95 (2017) e21394.

[36] K.J. Livak, T.D. Schmittgen, Analysis of relative gene expression data using Real-Time Quantitative PCR and the $2^{-\Delta \Delta C T}$ method, Methods 25 (2001) 402-408.

[37] W.S. Abbott, A method of computing the effectiveness of an insecticide, J. Econ. Entomol. 18 (1925) 265-267.

[38] K. Ichinose, D.V. Bang, D.H. Tuan, L.Q. Dien, Effective use of neonicotinoids for protection of citrus seedlings from invasion by Diaphorina citri (Hemiptera: Psyllidae), J. Econ. Entomol. 103 (2010) 127-135.

[39] S.C.T. Leong, F. Abang, A. Beattie, R.J.H. Kueh, S.K. Wong, Impacts of horticultural mineral oils and two insecticide practices on population fluctuation of Diaphorina citri and spread of Huanglongbing in a citrus orchard in Sarawak, Sci. World J. 2012 (2012) e651416.

[40] D.R. Boina, E.O. Onagbola, M. Salyani, L.L. Stelinski, Influence of posttreatment temperature on the toxicity of insecticides against Diaphorina citri (Hemiptera: Psyllidae), J. Econ. Entomol. 102 (2009) 685-691.

[41] N. Yu, O. Christiaens, J. Liu, J. Niu, K. Cappelle, S. Caccia, H. Huvenne, G. Smagghe, Delivery of dsRNA for RNAi in insects: an overview and future directions, Insect Sci. 20 (2013) 4-14.

[42] I. El-Shesheny, S. Hajeri, I. El-Hawary, S. Gowda, N. Killiny, Silencing abnormal wing disc gene of the Asian citrus psyllid, Diaphorina citri disrupts adult wing development and increases nymph mortality, PLoS One 8 (2013) e65392.

[43] E. Zerba, Insecticidal activity of pyrethroids on insects of medical importance, Parasitol. Today 4 (1988) S3-S7. 
1 [44] D.G. Sánchez, L.H. Otero, C.M. Hernández, A.L. Serra, S. Encarnación, C.E. Domenech,

2 Á.T. Lisa, A Pseudomonas aeruginosa PAO1 acetylcholinesterase is encoded by the $3 \quad$ PA4921 gene and belongs to the SGNH hydrolase family, Microbiol. Res. 167 (2012) $4 \quad 317-325$.

5 [45] Y. Lu, Y.P. Pang, Y. Park, X. Gao, J. Yao, X. Zhang, K.Y. Zhu, Genome organization, 6 phylogenies, expression patterns, and three-dimensional protein models of two $7 \quad$ acetylcholinesterase genes from the red flour beetle, PLoS One 7 (2012) e32288.

8 [46] H.J. Chen, Z. Liao, X.M. Hui, G.Q. Li, F. Li, Z.J. Han, Ace2, rather than Ace1, is the major 9 acetylcholinesterase in the silkworm, Bombyx mori, Insect Sci. 16 (2009) 297-303.

10 [47] Y. Lu, Y. Park, X. Gao, X. Zhang, J. Yao, Y.P. Pang, H. Jiang, K.Y. Zhu, Cholinergic and 11 non-cholinergic functions of two acetylcholinesterase genes revealed by gene-silencing in 12 Tribolium castaneum, Sci. Rep. 2 (2012) 288.

13

14 
1 Fig. 1. (A) Effect of five concentrations of dsRNA- $A C h E$ on the mortality percentages of the

2 fourth and fifth instar nymphs of Diaphorina citri, with simple linear regression plot of the

3 concentration of dsRNA- $A C h E$ versus mortality; (B) Effect of dsRNA- $A C h E$ concentrations on

4 the mortality of the adults of D. citri with simple linear regression plot of the concentration of

5 dsRNA- $A C h E$ versus mortality. RNase- free water was used as a control. Letters a, b, c, d, e and

6 f showing significant differences between the treatments $(P<0.05)$. Bars on columns represent

7 the standard error.

9 Fig. 2. Relative expression levels of three targeted genes treated with dsRNA in D. citri after 48

$10 \mathrm{~h}$ using qRT-PCR. (A,B,C and D) showed the expression levels of AChE-like-1, AChE-like-2 and

11 ChE-2-like in D. citri adults emerged from treated nymphs and; (E,F,G and $\mathrm{H})$ in the D. citri

12 treated adults. Actin gene were used to normalized the Ct values. $\alpha$-tubulin was used as a non-

13 target gene control. dsRNA- $g f p$ treatment was used as a control (irrelevant gene). Different

14 letters indicate statistically significant differences $(P<0.05)$

16 Fig. 3. Effect of dsRNA-AChE concentrations on $D$. citri susceptibility to four different

17 insecticides, with simple linear regression plot of the concentration of dsRNA- $A C h E$ versus

18 mortality. Mortality percentages of $D$. citri emerged adults from treated fourth and fifth instar

19 nymphs with dsRNA- $A C h E$ after exposure to A) carbaryl; B) chlorpyrifos; C) fenpropathrin; D)

20 imidacloprid at $\mathrm{LC}_{50}$ concentration for $24 \mathrm{~h}$ compared with $\mathrm{E}$ ) acetone as a control for the

21 insecticides. Different letters indicate the significant differences between the treatments $(P<$

22 0.05). Bars on columns illustrate the standard error. 
1 Fig. 4. Effect of five dsRNA-AChE concentrations on $D$. citri susceptibility to four different 2 insecticides, with simple linear regression plot of the concentration of dsRNA- $A C h E$ versus 3 mortality. A) Mortality of $D$. citri treated adults with dsRNA- $A C h E$ after treatment with

4 carbaryl; B) chlorpyrifos; C) fenpropathrin and D) imidacloprid at $\mathrm{LC}_{50}$ concentration for $24 \mathrm{~h}$ 5 compared with E) acetone as a control for the insecticides. The adults were transferred to non6 treated leaf discs for $48 \mathrm{~h}$ before exposure to the insecticides. Bars labeled with different letters

7 show significant differences between the treatments $(P<0.05)$. Bars on columns illustrate the 8 standard error. 

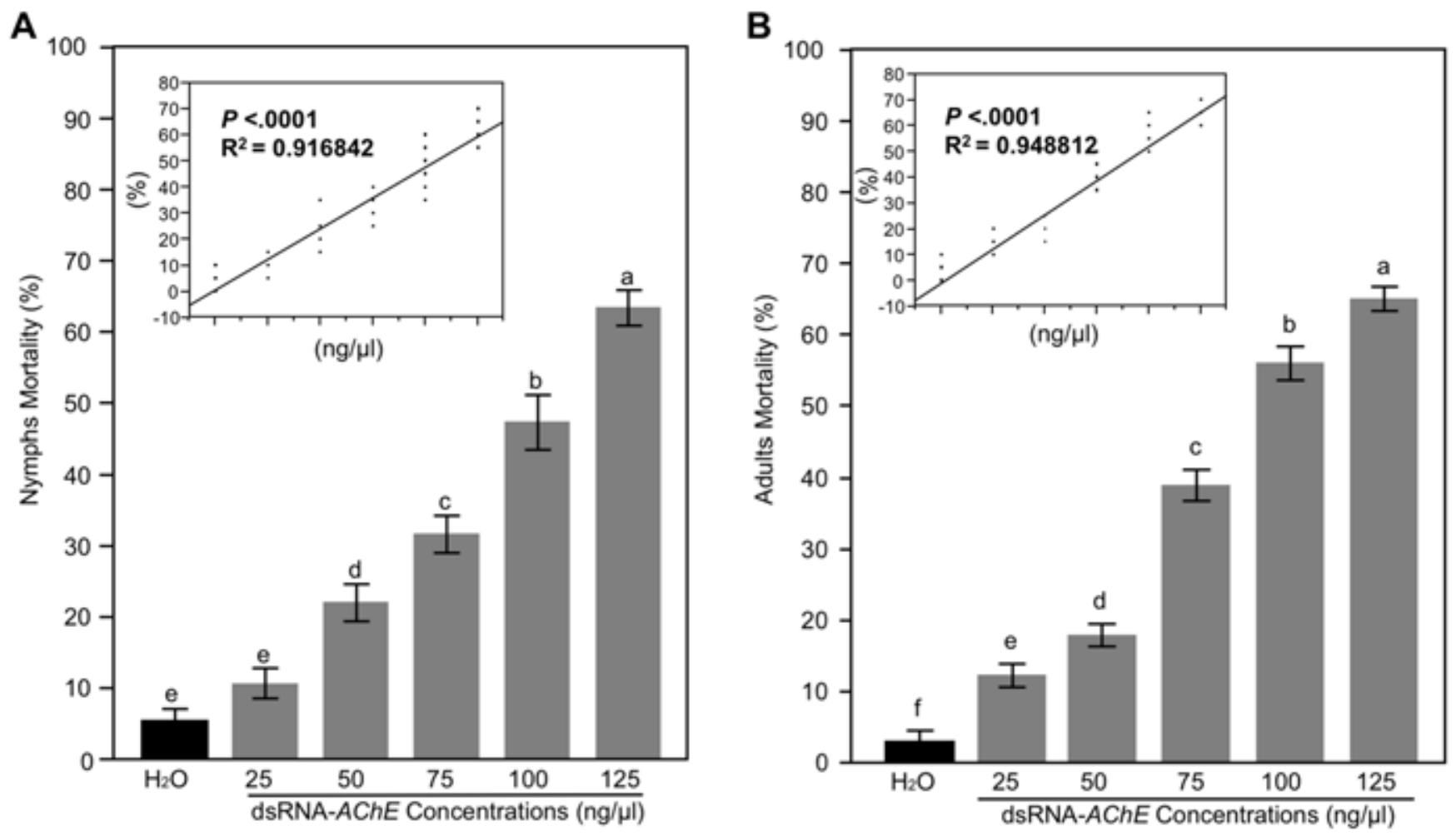

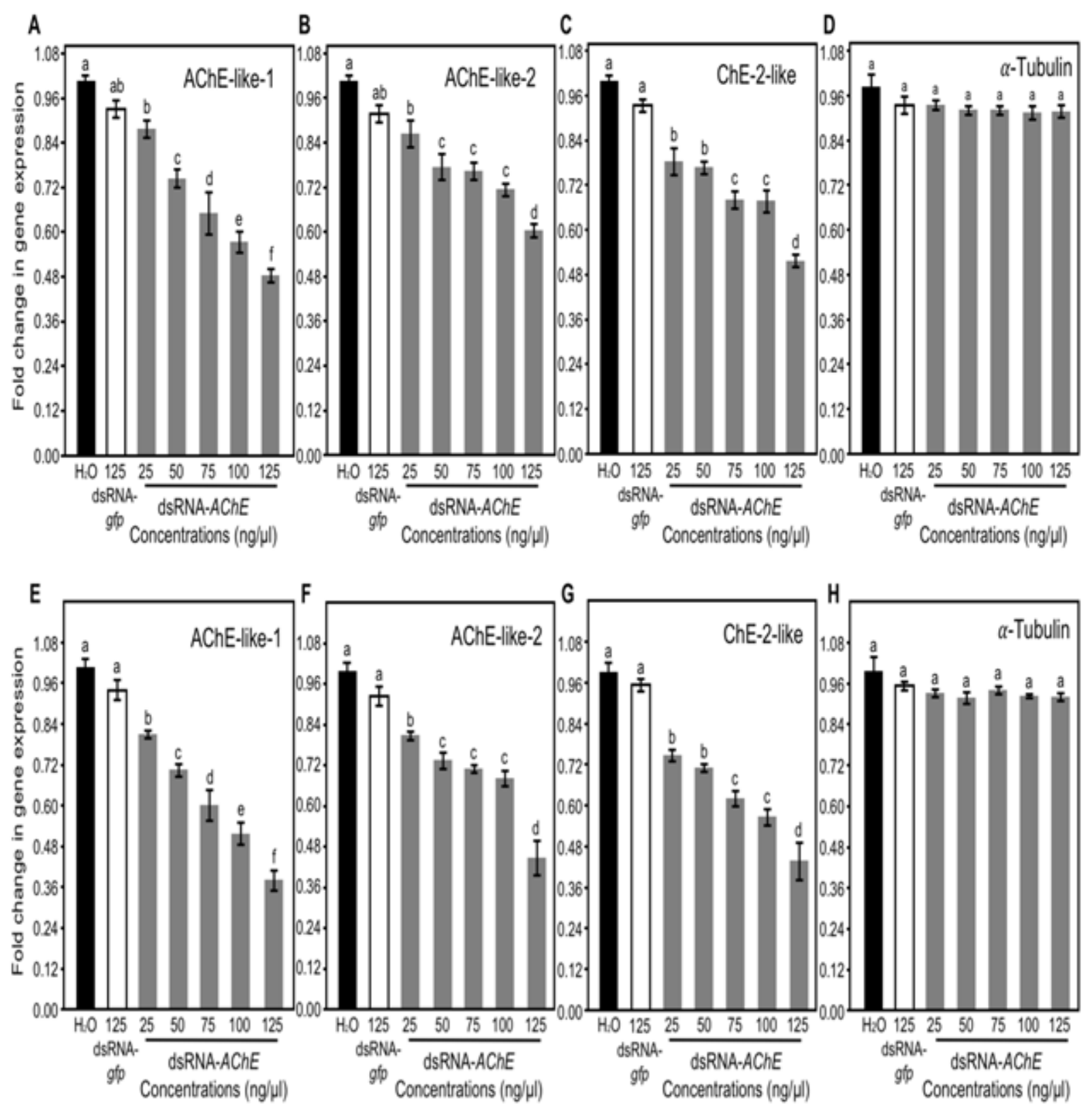

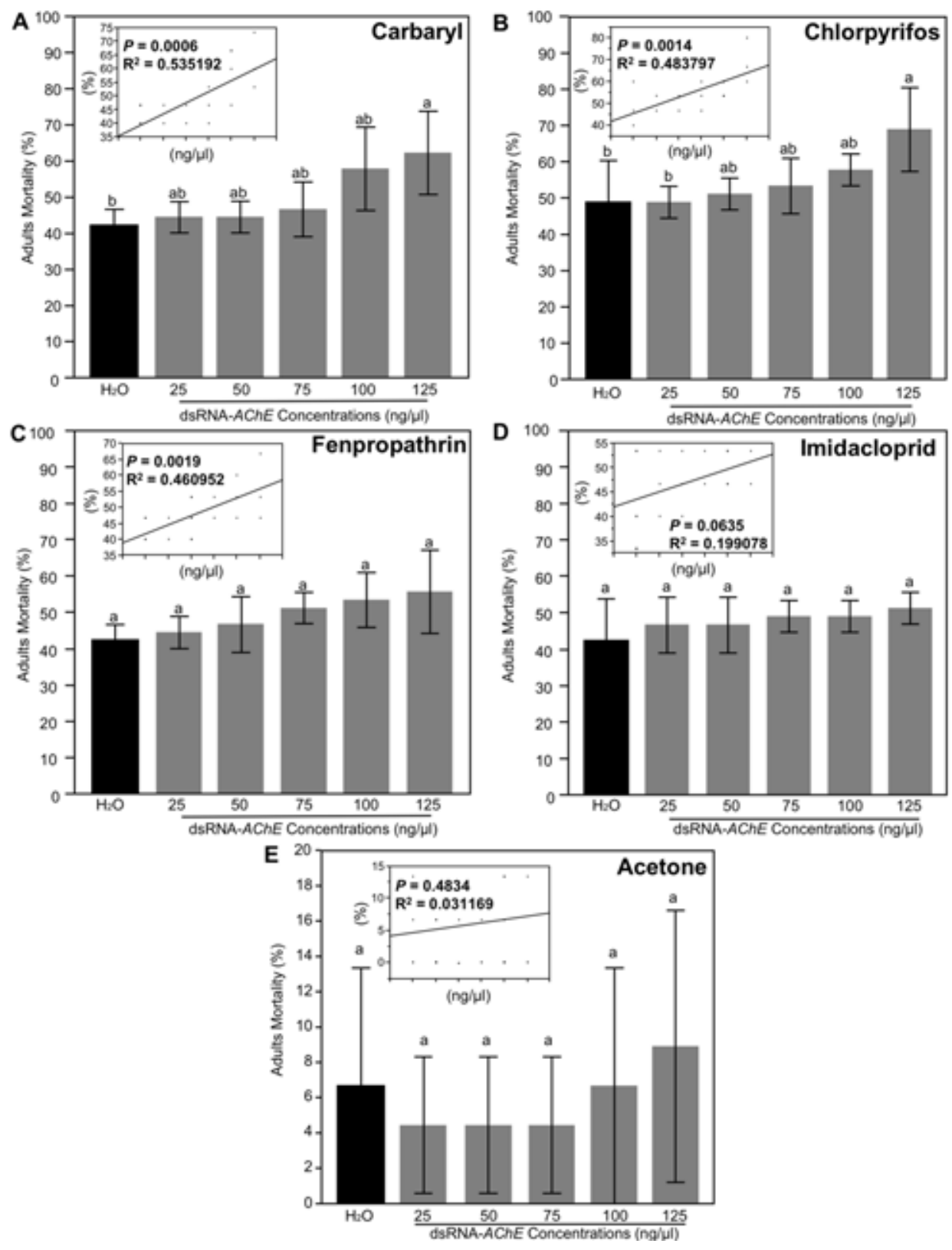

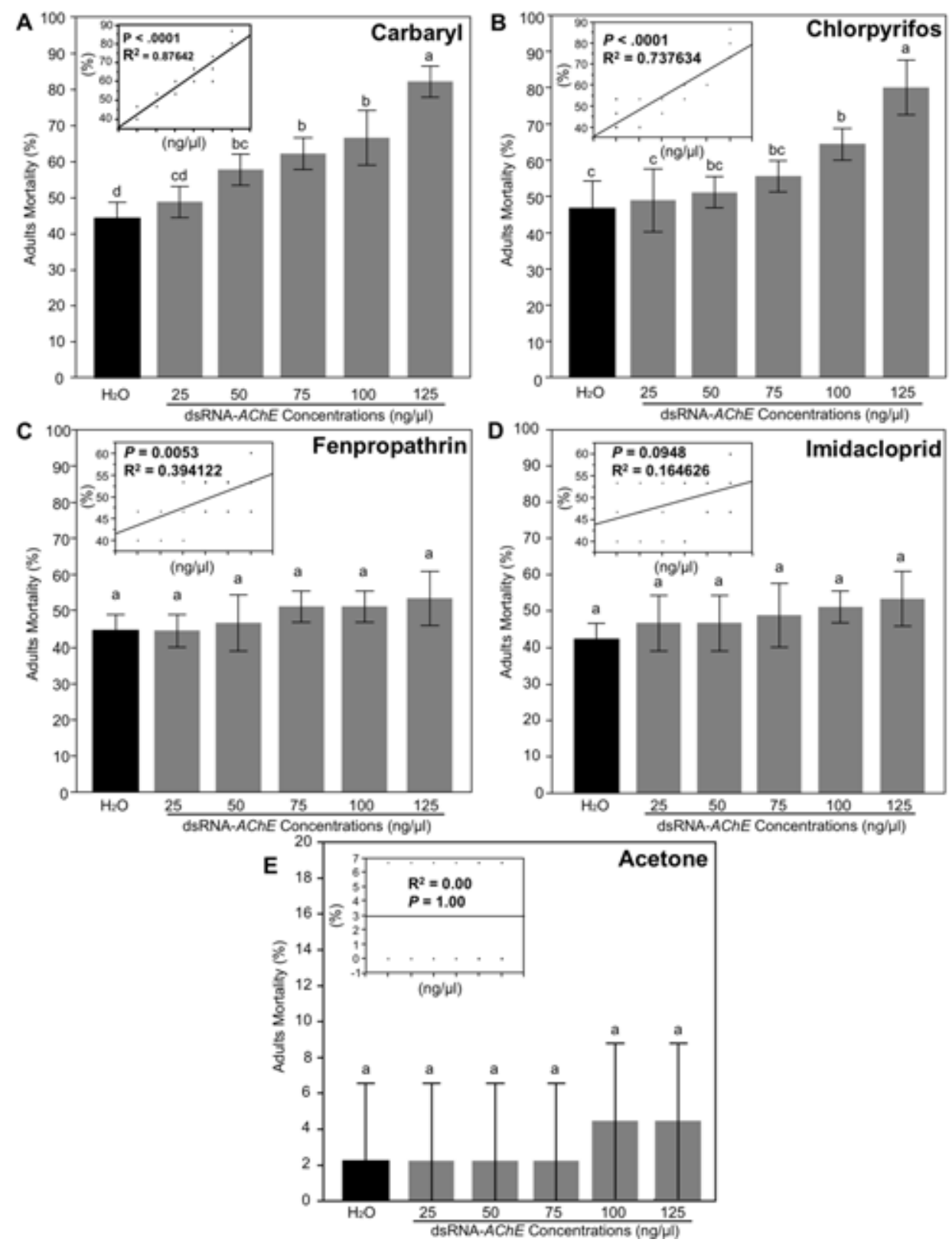


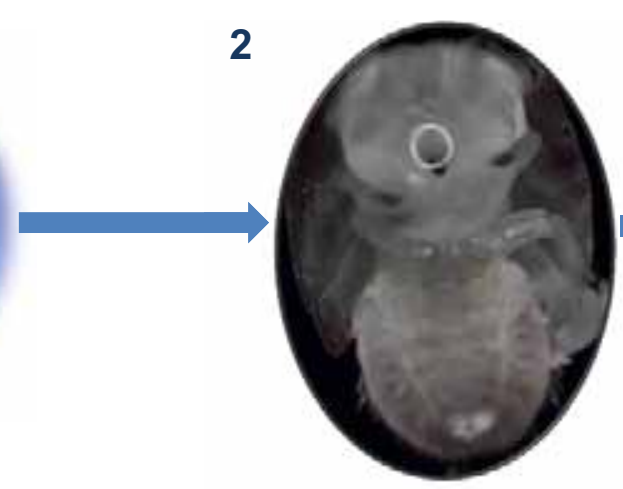

1. Application of dsRNA-AChE on $5^{\text {th }}$ instar nymphs.

2. Droplet of dsRNA-AChE is located between the three pairs of legs.

3. Transfer the treated nymphs are to a plant until emergence into adults.

4. Insecticide applications for the emerged adults using the leaf-dip bioassay.

5. Treatment using dsRNA-AChE increased the insecticide susceptibility of $D$. citri.
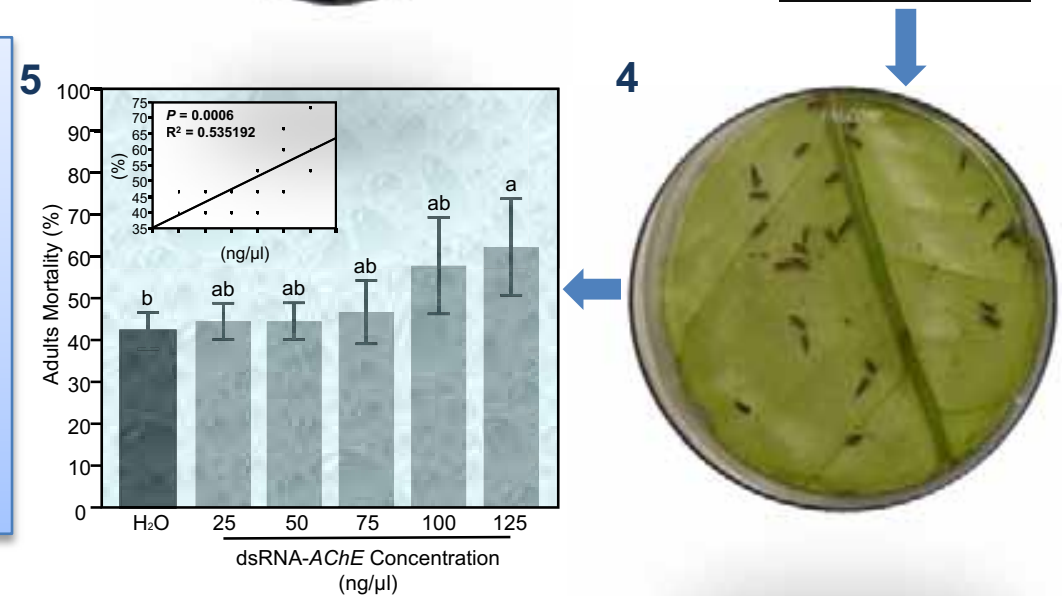

GRaphical ABstract 
Table 1. Details of the tested insecticides against $D$. citri adults

\begin{tabular}{|c|c|c|c|c|c|}
\hline $\begin{array}{c}\text { Common } \\
\text { name }\end{array}$ & Purity & Class & $\begin{array}{c}\begin{array}{c}\text { Targeted } \\
\text { system }\end{array} \\
\end{array}$ & Mode of Action & Manufacturer \\
\hline Chlorpyrifos & $99.5 \%$ & Organophosphate & \multirow{4}{*}{ 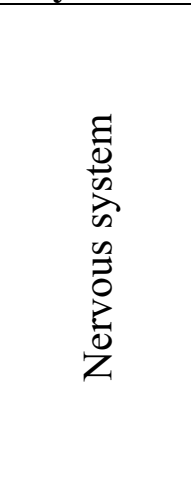 } & $\begin{array}{l}\text { Acetylcholinesterase } \\
\text { (AChEe) inhibitor }\end{array}$ & \multirow{2}{*}{$\begin{array}{c}\text { Chem service, } \\
\text { INC, West } \\
\text { Chester, PA }\end{array}$} \\
\hline Carbaryl & 9 & Carb & & $\begin{array}{l}\text { Acetylcholinesterase } \\
\text { (AChEe) inhibitor }\end{array}$ & \\
\hline Fenpropathrin & $99.1 \%$ & $\begin{array}{l}\text { Synthetic } \\
\text { pyrethroid }\end{array}$ & & $\begin{array}{c}\text { Sodium channel } \\
\text { modulator }\end{array}$ & \multirow[b]{2}{*}{$\begin{array}{l}\text { Sigma-Aldrich } \\
\text { Co. LLC., St. } \\
\text { Louis, MO }\end{array}$} \\
\hline Imidaclop & $99.9 \%$ & Neonicotinoids & & $\begin{array}{c}\text { Nicotinic } \\
\text { acetylcholine } \\
\text { receptor (nAChR) } \\
\text { agonist }\end{array}$ & \\
\hline
\end{tabular}


S0048357517302638_Abdelaziz_Kishk_Diaphornia_citri_2017 Table 2. Toxicity of four insecticides on lab population of $D$. citri adults

\begin{tabular}{|c|c|c|c|c|c|}
\hline Insecticides & 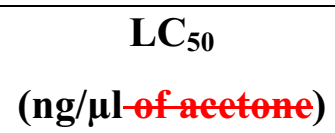 & Lower 95\% & Upper 95\% & Slope \pm SE & $P$ valute \\
\hline Chlorpyrifos & $2.62^{c}$ & 1.85 & 3.51 & $0.602 \pm 0.062$ & $\begin{array}{r}<.0001 \\
6 \\
\end{array}$ \\
\hline Carbaryl & $12.04^{\mathrm{a}}$ & 9.88 & 14.43 & $1.046 \pm 0.099$ & $<.0007$ \\
\hline Fenpropathrin & $4.85^{\mathrm{b}}$ & 2.68 & 7.81 & $0.414 \pm 0.044$ & $<.0001$ \\
\hline Imidacloprid & $0.34^{d}$ & 0.25 & 0.48 & $0.455 \pm 0.043$ & $\begin{array}{r}<.0001 \\
10\end{array}$ \\
\hline
\end{tabular}

Different superscript letters in the same column indicate significant differences among the $\mathrm{LC}_{50}$ values. 